\title{
Hemophagocytic Syndrome In Association With Systemic Lupus Erythematosus and Rheumatoid Arthritis
}

\author{
Mohammad Esmadia, c, Muhammad O. Khokhar ${ }^{\mathrm{a}}$, Dina S. Ahmad ${ }^{\mathrm{a}}$, Donald C. Doll ${ }^{\mathrm{b}}$
}

\begin{abstract}
Hemophagocytic syndrome (HPS) is a potentially life-threatening complication of rheumatic disorders characterized by the infiltration of morphologically benign hemophagocytic macrophages in the bone marrow and in various other organs. It is known to be associated with several conditions, such as viral or bacterial infection, malignancies, and autoimmune diseases such as systemic lupus erythematosus (SLE) and adult onset Still's disease and less commonly with rheumatoid arthritis (RA). We report a case of a 59-year-old lady known to have SLE and RA who developed worsening anemia, thrombocytopenia, coagulopathy, renal failure and was diagnosed with hemophagocytic syndrome. In spite of aggressive supportive management, intravenous steroids and immunoglobulins, the patient eventually died due to intracranial bleeding. Although cases of HPS have been previously described in association with SLE or RA, this is the first case of HPS to our knowledge to be diagnosed in a patient who had both RA and SLE.
\end{abstract}

Keywords: Hemophagocytic syndrome; Systemic lupus erythematosus; Rheumatoid arthritis; Lymphohistiocytoses

\section{Introduction}

Hemophagocytic syndrome (HPS) is an entity characterized

Manuscript accepted for publication March 13, 2012

${ }^{\mathrm{a}}$ Department of Internal Medicine, University of Missouri School of Medicine, Columbia, MO, USA

${ }^{\mathrm{b}}$ Division of Hematology and Medical Oncology, Department of Internal Medicine, University of Missouri School of Medicine, Columbia, MO, USA

${ }^{\mathrm{c}}$ Corresponding author: Mohammad Esmadi, One Hospital Dr., DC043.00 Health Sciences Center, Columbia, MO 65212, USA.

Email:mohsmadi@hotmail.com

doi: $10.4021 / \mathrm{jmc} 589 \mathrm{w}$ by the activation of macrophages and/or histiocytes with prominent hemophagocytosis in bone marrow and other reticuloendothelial systems [1]. HPS comprises primary (hereditary) and reactive forms. Primary HPS denotes the presence of an underlying genetic disorder and is observed mostly in infants. Reactive HPS occurs in situations such as infections, malignant lymphomas, a variety of autoimmune diseases including lupus erythematosus, rheumatoid arthritis, Still's disease, polyarteritis nodosa, mixed connective tissue disease, pulmonary sarcoidosis, systemic sclerosis, and Sjogren's syndrome, and certain drugs [2-4]. Clinical features of HPS include fever, cytopenia, liver enzyme elevation, hepatosplenomegaly, lymphadenopathy, elevated ferritin levels, hypertriglyceremia and coagulopathy [5].

\section{Case Report}

We describe a 59-year-old white female who is known to have systemic lupus erythematousus (SLE) and rheumatoid arthritis (RA), on methotrexate $2.5 \mathrm{mg}$ every week, and prednisone $5 \mathrm{mg}$ daily who presented with nausea, vomiting, diarrhea and fatigue over a period of one week. Her vital signs were stable and her physical examination was unremarkable. On admission, her creatinine was $4.4 \mathrm{mg} / \mathrm{dL}$, hemoglobin $14.4 \mathrm{gm} / \mathrm{dl}$, platelets $110,000 / \mathrm{mcL}$, white cell count $3210 / \mathrm{mcL}$, total bilirubin $0.2 \mathrm{mg} / \mathrm{dL}$, AST $47 \mathrm{unit} / \mathrm{L}$, ALT 46 unit/L, alkaline phosphatase 193 unit/L, total protein $7.7 \mathrm{~g} / \mathrm{dL}$, albumin $3.9 \mathrm{~g} / \mathrm{dL}$, lactate dehydrogenase (LDH) 491 unit/L, INR 0.9 and partial thromboplastin time (PTT) 58 seconds.

Soon after admission, however, she started to spike fevers and her hemoglobin dropped from $14.4 \mathrm{gm} / \mathrm{dl}$ to 10.4 $\mathrm{gm} / \mathrm{dL}$, and platelets dropped to $53,000 / \mathrm{mcL}$. Her PTT increased to 70 seconds. Peripheral smear showed normocytic cells with burr cells and thrombocytopenia, but no shistocytes. PTT mixing study corrected partially with PTT remaining elevated at 39.7 seconds. Factor V Assay was $97 \%$, factor IX $67 \%$, factor X $100 \%$, factor VII $182 \%$ and factor VIII-C 236\%. Thrombin time was 60 seconds. She received prophylactic subcutaneous heparin during the first 3 days of her hospitalization, but platelet factor $4(\mathrm{PF} 4)$ antibody was 


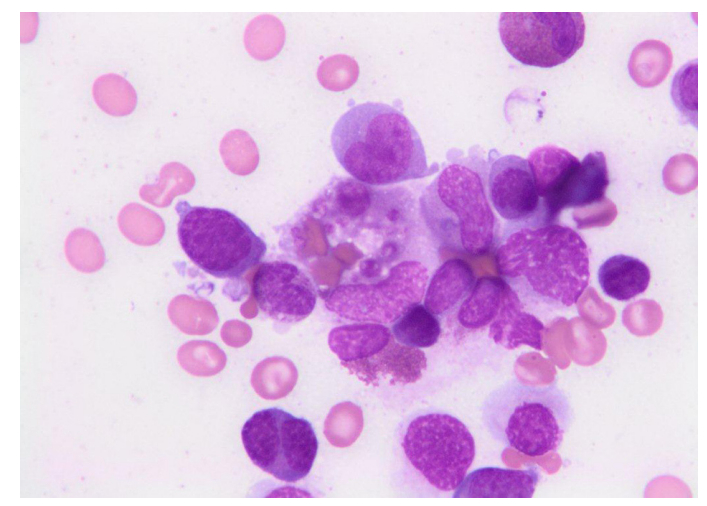

Figure 1. Bone marrow biopsy showing hemophagocytic macrophages.

normal. Her fibrinogen had always been greater than 190 $\mathrm{mg} / \mathrm{dL}$. The patient also tested negative for HIV, EBV and viral hepatitis.
Bone marrow biopsy was done on day 5. After the bone marrow biopsy the patient began to bleed from the biopsy site along with mucosal and subcutaneous bleeding. Her PTT at this point was around 100 seconds. She became hypotensive and was transferred to the ICU and started on broad spectrum antibiotics. All cultures were negative. Due to worsening anemia, she required 10 units of blood along with multiple units of fresh frozen plasma and cryoprecipitate. Her platelets continued to drop down to $8000 / \mathrm{mcL}$.

On day number 7, the bone marrow biopsy result came back as $15 \%$ plasma cells with hemophagocytic macrophages (Fig. 1), raising the suspicion for HPS. Moreover, ferritin level was $17289 \mathrm{ng} / \mathrm{mL}$ and triglycerides level was elevated at $657 \mathrm{mg} / \mathrm{dL}$. The patient was started on Methylprednisolone $1000 \mathrm{mg}$ /day and intravenous immunoglobulins (IVIG) $1 \mathrm{~g} / \mathrm{kg} /$ day. Her kidney function continued to deteriorate and required dialysis eventually. Her level of consciousness also started to deteriorate. Her platelets and hemoglobin contin-

Table 1. Revised Diagnostic Guidelines for Hemophagocytic Lymphohistiocytosis (HLH)

\section{Diagnosis of HLH is established if either one or both of the criteria below are fulfilled}
(1) A molecular diagnosis consistent with HLH
(2) Diagnostic criteria for HLH fulfilled ( $\geq 5$ of the 8 criteria below)

Fever

Splenomegaly

Cytopenias affecting $\geq 2$ of 3 lineages in peripheral blood:

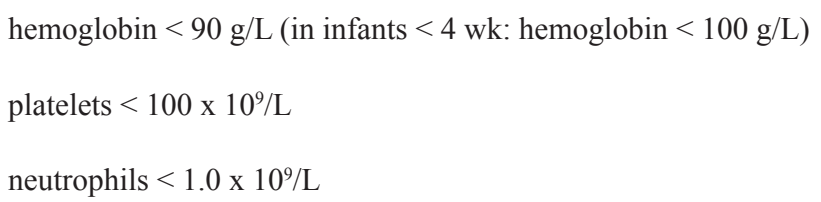

Hypertriglyceridemia and/or hypofibrinogenemia:

fasting triglycerides $\geq 3.0 \mathrm{mmol} / \mathrm{L}(\geq 265 \mathrm{mg} / \mathrm{dL})$

fibrinogen $\leq 1.5 \mathrm{~g} / \mathrm{L}$

Hemophagocytosis in bone marrow, spleen, lymph nodes or cerebrospinal fluid:

no evidence of malignancy

Low or absent natural killer cell activity (according to local laboratory reference)

Elevated ferritin $(\geq 500 \mu \mathrm{g} / \mathrm{L})$

Soluble CD25 (namely, soluble interleukin-2 receptor) $\geq 2400 \mathrm{U} / \mathrm{mL}$ 
ued to drop and required repeated transfusions of platelets and blood. IVIG was stopped on day 9. On day number 10, her triglycerides dropped to $525 \mathrm{mg} / \mathrm{dL}$ and ferritin dropped to $7,791 \mathrm{ng} / \mathrm{mL}$. On day 11 , she had a negative work up for ANCA and anti-cardiolipin antibodies. ADAMTS13 activity was decreased at $58 \%$.

On day 12 , the patient had even more worsening of her level of consciousness. MRI indicated diffuse cortical necrosis/hemorrhage. Given, the MRI findings and the worsening renal failure, coagulopathy, anemia and thrombocytopenia, the decision was to defer any further aggressive supportive measures and she eventually died.

\section{Discussion}

The widely used criteria for diagnosing MAS are the hemophagocytic lymphohistiocytosis (HLH) criteria, which include fever, splenomegaly, cytopenias affecting at least two of three lineages in the peripheral blood, hypertriglyceridemia and/or hypofibrinogenemia, hemophagocytosis in bone marrow, spleen or lymph nodes, low or absent natural killer cell activity, hyperferritinemia, and high levels of sIL-2r (Table 1). Altogether, five of the eight criteria must be fulfilled; patients with a molecular diagnosis consistent with HLH do not necessarily need to fulfill the diagnostic criteria [6-9].

In a study done by Fukaya et al, the prevalence of HPS among inpatients with autoimmune diseases was 3.0\%. HPS was most prevalent in patients with adult onset Still's disease, followed by Sjogren's Syndrome and SLE. At the time when the diagnosis of HPS was made, fever was observed in $87 \%$ of the patients. Neuropsychiatric manifestations were noted in 30\%. Leukopenia, anemia or thrombocytopenia was found in 87,83 or $87 \%$, respectively. CRP was elevated in $83 \%$ of the patients. Liver enzyme elevation (aspartate aminotransferase or LDH), more than two times the upper normal limit, was observed in $60 \%$. Median ferritin level was $980 \mathrm{ng} / \mathrm{ml}$. Factors related with mortality were age over 50 years, the presence of infection, leucocyte count $<0.5 \mathrm{x}$ $10^{9} / \mathrm{L}$, platelet count $<50 \times 10^{9} / \mathrm{L}$ and CRP level $<50 \mathrm{mg} / \mathrm{L}$ at the onset of HPS. [5] Current treatment strategy include induction therapy over an eight-week period with dexamethasone, etoposide (VP-16), and intrathecal methotrexate, followed by cyclosporine (trough levels of $200 \mu / \mathrm{L}$ ) started at week 9 , along with pulses of dexamethasone and etoposide for up to one year [6].

Our patient had fever, bicytopenia, hepatic dysfunction, hypertriglyceridemia, hyperferritinemia and hemophagocytic macrophages on bone marrow aspirate. The ADAMS13 of $58 \%$ is non-specific and could be explained by the liver disease the patient had. Plasma cells in the bone marrow biopsy are related to the connective tissue disease the patient had rather than multiple myeloma. HPS might have been precipitated by an undetected gastroenteritis or the connective tis- sue diseases. The drop in ferritin and triglycerides indicates response to Methylprednisolone and IVIG. Although cases of HPS were previously described to be associated with SLE or RA, this is the first case of HPS to our knowledge to be reported in a patient who had both RA and SLE.

\section{Acknowledgment}

Work done at University of Missouri School of Medicine, Columbia, MO.

\section{Conflict of Interest}

No conflict of interest.

\section{Grant Support}

No Funding.

\section{References}

1. Imashuku S. Differential diagnosis of haemophagocytic syndrome: underlying

disorders and selection of the most effective treatment. Int $\mathrm{J}$ Hematol. 1997;66:135-51.

2. Kumakura S, Ishikura H, Umegae N, Yamagata S, Kobayashi S. Autoimmune-associated hemophagocytic syndrome. Am J Med. 1997;102(1):113-115.

3. Dhote R, Simon J, Papo T, Detournay B, Sailler L, Andre MH, Dupond JL, et al. Reactive hemophagocytic syndrome in adult systemic disease: report of twenty-six cases and literature review. Arthritis Rheum. 2003;49(5):633-639.

4. Arlet JB, Le TH, Marinho A, Amoura Z, Wechsler B, Papo T, Piette JC. Reactive haemophagocytic syndrome in adult-onset Still's disease: a report of six patients and a review of the literature. Ann Rheum Dis. 2006;65(12):1596-1601.

5. Fukaya S, Yasuda S, Hashimoto T, Oku K, Kataoka H, Horita T, Atsumi T, et al. Clinical features of haemophagocytic syndrome in patients with systemic autoimmune diseases: analysis of 30 cases. Rheumatology (Oxford). 2008;47(11):1686-1691.

6. Henter JI, Elinder G, Ost A. Diagnostic guidelines for hemophagocytic lymphohistiocytosis. The FHL Study Group of the Histiocyte Society. Semin Oncol. 1991;18(1):29-33.

7. Henter J-I, Tondini C, Pritchard J. Histiocytic syndromes. Crit Rev Oncol Hematol. 2004;50:157-74.

8. Kelly A, Ramanan AV. Recognition and management of 
macrophage activation syndrome in juvenile arthritis. Curr Opin Rheumatol. 2007;19(5):477-481.

9. Henter JI, Horne A, Arico M, Egeler RM, Filipovich AH,
Imashuku S, Ladisch S, et al. HLH-2004: Diagnostic and therapeutic guidelines for hemophagocytic lymphohistiocytosis. Pediatr Blood Cancer. 2007;48(2):124-131. 